\title{
Development of Salt Leached Silk Fibroin Scaffold using Direct Dissolution Techniques for Cartilage Tissue Engineering
}

\author{
Untung Ari Wibowo", Hermawan Judawisastra ${ }^{\#}$, Anggraini Barlian ${ }^{*}$, Nayla M. Alfarafisa*, \\ Karina F Moegni ${ }^{+}$Melinda Remelia ${ }^{+}$ \\ ${ }^{\#}$ Materials Science and Engineering Department, Faculty of Mechanical and Aerospace Engineering, Institut Teknologi Bandung, Bandung, \\ Indonesia \\ E-mail: untung@ftmd.itb.ac.id; hermawan.judawisastra@material.itb.ac.id
}

*School of Life Science and Technology, Institut Teknologi Bandung, Bandung, Indonesia

E-mail:aang@sith.itb.ac.id; naylaalfarafisa@yahoo.com

${ }^{+}$Hayandra Foundation, Jakarta, Indonesia

E-mail: karina@hayandra.com; melindaremelia@gmail.com

\begin{abstract}
Autologous transplantations, the gold standard, did not meet sufficient health tissue coverage area for cartilage damage treatments. The field of tissue engineering offers a promising alternative to fulfill this limitation by growing patient own cells on biomaterials through tissue culture, reconstructed into new cartilage tissue, and the implanted to the injury area. To support tissue regeneration, biocompatible, biodegradable, and high strength silk fibroin (SF) was proposed in this study as scaffold materials. In this research, direct dissolution in $\mathbf{C a C l}_{2}$ /formic acid, a faster and simpler process than traditional dissolution techniques, combined with salt leaching technique. SF contents on the scaffold were varied from $2 \mathrm{w} / \mathrm{v} \%$ to $12 \mathrm{w} / \mathrm{v} \%$ and NaCl size as porogen was fixed in diameter of $250 \pm 58 \mu \mathrm{m}$. Evaluation of the SF scaffold's morphology, hydrophilicity, biodegradability, and biocompatibility were conducted. The results showed porous silk fibroin scaffold had been successfully developed. The SF scaffolds have pore size 261-293 $\mu \mathrm{m}$ with highly interconnected pores. FTIR and XRD analysis of the scaffolds showed the characteristics of silk fibroin, which reveals the $\alpha$-helix amorphous and $\beta$-sheet crystalline structure and comparable to the silk fibers. The scaffold showed good hydrophilicity and high water uptakes, which essential properties for cell survival. The scaffold degraded under Protease XIV, indicate biodegradable properties. Observation of cell attachment confirms the scaffold has good biocompatibility to adipose-derived stem cells and are suitable to be used in cartilage tissue engineering.
\end{abstract}

Keywords— direct dissolution; porous scaffold; salt leaching; silk fibroin; tissue engineering.

\section{INTRODUCTION}

Damaged cartilage due to disease and injury can lead to tissue degeneration in the human body, which need advanced treatments to support their repair. The current gold standard in tissue damage treatment was transplantation of healthy tissue from one site to another in the same patient (autologous transplants) or from different person to the patient (allograft transplants). The significant problems both in autologous or allograft transplant were limited coverage area of healthy tissue left in the patient body and limited donor number[1]. New transplant source is required to overcome this limitation. The field of tissue engineering offers a promising alternative for damage tissue repair by growing patient own cells on biomaterials through tissue culture, reconstructed into targeted tissue, and then implanted to the injury area to regenerate the damaged area [2], [3].

During tissue reconstruction processes, a scaffold material with highly porous structure is required to support cell growth, nutrient transport, and tissue development. Scaffold materials should meet structural and functional properties such as high strength properties, biocompatible, and biodegradable [3]. Pore size and interconnectivity of pores are also importance morphological characteristics of scaffolds that have a direct influence on the cell-to-cell interactions and mass transport processes which critical for cell survival [2]. Another important requirement is that the degradation rate of the scaffold should match the rate of new tissue remodeling. Therefore, altering and controlling the morphological characteristics and degradation rate of scaffold materials are essential subjects to be studied. 
Silk fibroin (SF), a protein-based material secreted by Bombyx mori silkworm, has extensively used as a suture material for centuries due to its high strength and biocompatibility, and its slow rate of degradation. The application of silk fibroin as tissue engineering scaffold has been widely studies into various material formats such as Nano fibers, hydrogel, and porous materials [4]. For cartilage tissue engineering, the porous scaffold was more suitable compared to others [5]. Usually, the methods used to generate SF porous scaffold begins with two steps: SF dissolution in strong inorganic salt such $\mathrm{LiBr}$, followed by dialysis (3-4 days) to remove the salt and then freeze-dried to obtain regenerated silk (Fig. 1). The SF porous scaffolds have been produced from this regenerated silk using freeze drying, gas foaming, and salt leaching methods [6]. However, this traditional dissolution method takes time-consuming, temperature sensitive and complex processes. Zhang et al. developed a direct dissolution method using $\mathrm{CaCl}_{2}$-formic acid mixture to form SF film [7] and fiber [8] which exhibited simpler and faster processes. Currently, there is no study regarding the fabrication of porous SF scaffold using $\mathrm{CaCl}_{2}$-formic acid direct dissolution.

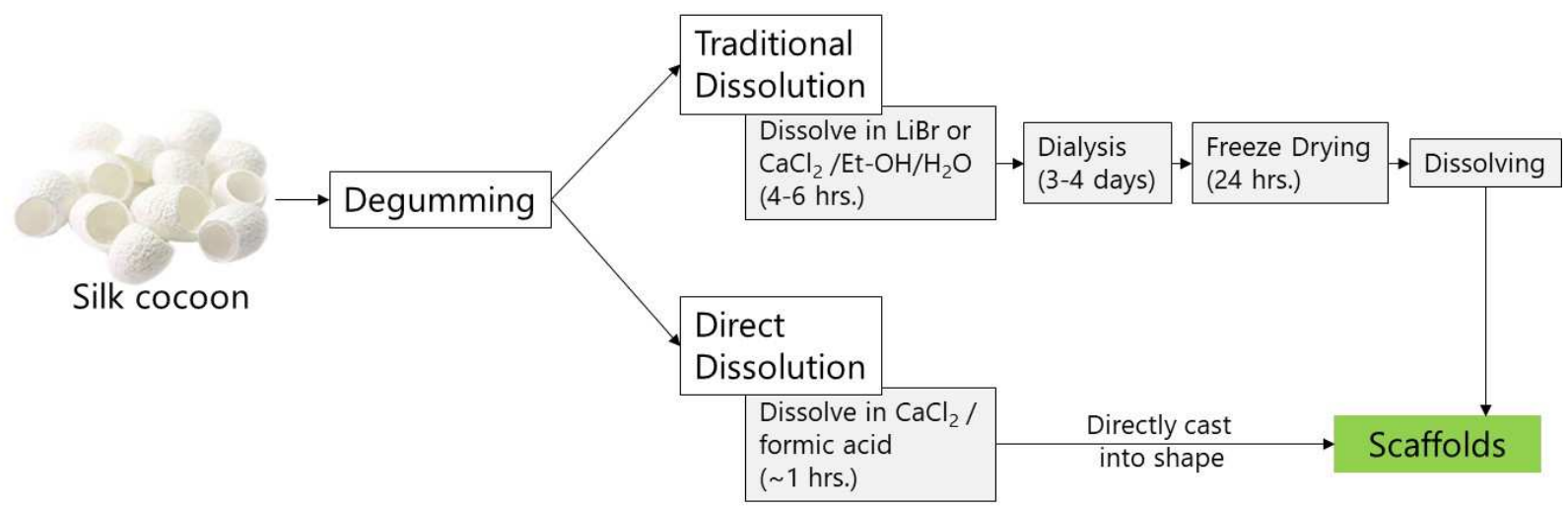

Fig. 1 Comparison of traditional dissolution and direct dissolution method to fabricate salt leached SF scaffold.

Salt leaching was widely used to produce scaffold because of easiness pore size control by variating the salt particle size as the porogen [9]-[12]. Salt leached silk fibroin scaffold has been successfully produced by traditional dissolution commonly using the Hexafluoroisopropanol (HFIP) solvent [6], as well as the aqueous solution [13]. In the present study, direct dissolution method using $\mathrm{CaCl}_{2}$ formic acid was developed in combination with salt leaching fabrication to produce porous silk fibroin scaffold. As illustrated in Fig. 1, the direct dissolution was significantly reduced the processing time and temperature. This combination will result in fast and controlled porous silk fibroin scaffold. Evaluation on the scaffold's morphology, structure, water uptakes, biodegradability, and biocompatibility will be carried out. The study of biodegradability was carryout using Protease XIV, as the previous study showed randomly attacking modes compared to others [14].

\section{MATERIALS AND METHODS}

\section{A. Materials}

Bombyx mori silkworm cocoon was obtained from CV. Wisata Ilmu Sutera, Bandung, Indonesia. Demineralized water, sodium bicarbonate, and sodium chloride were purchased from PT Bratachem, Bandung, Indonesia. Calcium chloride, formic acid, Dimethylsulfoxide (DMSO), and absolute ethanol were purchased from Merck Millipore, Germany. DMEM basal medium, Phosphatase Buffer Saline (PBS), Penicillin, Streptomycin, Fetal Bovine Serum (FBS), Cacodylate Buffer, and Protease XIV were purchased from Sigma Aldrich, USA. Adipose-derived Stem Cells (AdSCs) used in this study was obtained from Hayandra Foundation, Jakarta, Indonesia.

\section{B. Preparation of the Silk Fibroin Scaffold}

The porous silk fibroin (SF) scaffold fabrication was started by degummed the silk cocoon twice in $0.5 \mathrm{wt} \%$ $\mathrm{NaHCO}_{3}$ for 1 hour to remove the sericin, rinsed with demineralized water and then dried in a fume hood overnight. The degummed silk was directly dissolved in 8 -wt $\%$ $\mathrm{CaCl}_{2}$-formic acid using magnetic stirrer. The fibroin contents were varied 2, 4, 6, 8, 10 and 12 w/v\%, homogenized for 3 hours and then poured into $\mathrm{NaCl}$ containing mold ( $2.5 \mathrm{~cm}$ diameter) and then mixed manually using glass rod. The average $\mathrm{NaCl}$ sizes used were used $250 \pm 58 \mu \mathrm{m}$, manually sieved before used. NaCl-silk mixture ratio was fixed at gr-weight to ml-volume ratio 5:1. For biocompatibility study, the scaffolds were fabricated using a $5 \mathrm{~cm}$ diameter mold. The NaCl-silk mixture was then placed in a fume hood overnight to evaporate the solvent. After dried, the silk- $\mathrm{NaCl}$ block was immersed in $70 \%$ ethanol for 1 hour, followed by immersing into demineralized water for three days to remove the salt with changing the water every 6 hours.

\section{Characterization of Silk Fibroin Porous Scaffold}

1) Scaffold Morphology Examination: Scaffold morphology was determined by measuring pore size and pore interconnectivity using Scanning Electron Microscopy (SEM). The scaffolds were cut off approximately $1 \mathrm{~cm}^{2}$ square in liquid nitrogen to prevent pore deformation using a razor blade and then observed using SEM (Hitachi SU3500, Japan). In this study, low voltage of 1 to $1.5, \mathrm{keV}$ was used 
without any gold/carbon coating. The average pore sizes were determined by measuring 50 random pores selected randomly from each sample using Digimizer software (MedCalc Software bvba, Belgium).

2) Fourier Transformation Infrared (FTIR) Spectroscopy and X-ray diffraction (XRD): Fourier Transformation Infrared (FTIR) Spectroscopy and X-ray diffraction (XRD) techniques were utilized to analyze the structural features of the degummed silk fiber and the formed SF samples. The FTIR spectra were recorded from $400 \mathrm{~cm}^{-1}$ to $2250 \mathrm{~cm}^{-1}$ with 32 scans (Shimadzu IR Prestige21, Japan). X-ray diffraction (XRD) assessment was carried out using monochromatic $\mathrm{Cu}-\mathrm{K} \alpha$ radiation $(30 \mathrm{~mA}, 40 \mathrm{kV})$ with a scanning speed of $1 \%$ min (Bruker D8 Advance, USA).

3) Contact Angle and Water Uptakes: Scaffold hydrophilicity were investigated by static contact angle measurement on the SF film with 6, 8, 10 and $12 \mathrm{w} / \mathrm{v} \%$. The static contact angle was measured by dropping a $30-\mu l$ drop of water, and then the shape of the water drop was captured using the portable microscope (Dino-Lite, Taiwan). Water uptakes was also measured as the evaluation of scaffold ability to absorb water. The dry scaffold was weighed $\left(\mathrm{W}_{\mathrm{d}}\right)$, then immersed in water at room temperature for $24 \mathrm{~h}$. After excess water was removed using tissue paper, the wet weight of the scaffold $\left(\mathrm{W}_{\mathrm{s}}\right)$ was determined. The water uptakes of the scaffolds was calculated as follow:

$$
\text { Water Uptakes }(\%)=\left(\mathrm{W}_{\mathrm{s}}-\mathrm{W}_{\mathrm{d}}\right) / \mathrm{W}_{\mathrm{d}} \times 100 \% \text {. }
$$

4) Biodegradability Assessment: Enzymatic degradation in Protease XIV were adapted as biodegradability assessment methods. Dry scaffold piece with defined mass $\sim 200 \mathrm{mg}$ was placed into a 24-well plate in the respective control and Protease XIV solution $(1 \mathrm{U} / \mathrm{mL}$ in control PBS solution, $\mathrm{pH}$ 7.4). The solutions were replaced daily. The scaffolds were collected at 1, 3, 7, and 14 days, and the excess solution was blotted dried by using a tissue paper. The collected samples were weight by using an analytical balance with $\pm 0.1 \mathrm{mg}$ accuracy.

5) Biocompatibility Assessment: Biocompatibility of the scaffold was assessed by observation on cell attachment on the scaffolds prepared with six w/v\% and $12 \mathrm{w} / \mathrm{v} \%$ silk. SEM was used to determine scaffold biocompatibility by observing the morphology of the cell-seeded on the SF scaffolds. The scaffolds (4 $\mathrm{mm}$ diameter, $2 \mathrm{~mm}$ thickness) were steam sterilized at $121^{\circ} \mathrm{C}$ for $15 \mathrm{~min}$, followed by conditioning in complete DMEM medium overnight before cell seeding. A total $1 \times 10^{5}$ Adipose-derived Mesenchymal Stem Cells (AdSCs) were suspended in $10 \mu \mathrm{L}$ medium to achieve efficient seeding on the scaffold matrix. After 3 hours of incubation for initial cell attachment, additional $500 \mu \mathrm{L}$ DMEM was added. Incubation was conducted at $37^{\circ} \mathrm{C}$ and $5 \% \mathrm{CO}_{2}$ saturation. After incubation for one day, the seeded scaffolds were rinsed with PBS ( $\mathrm{pH} 7.4$ ), then fixed in $2.5 \mathrm{v} / \mathrm{v} \%$ Cacodylate Buffer overnight at $4^{\circ} \mathrm{C}$. The fixed samples were dehydrated with the gradient of alcohol (60-100\%), followed by drying with critical point drying. After sputter-coated with gold, samples were examined with SEM (Hitachi SU3500, Japan).

\section{RESULTS AND DISCUSSION}

\section{A. Scaffold Formation and Morphology}

Fig. 2 shows SEM images of the cross-sectional scaffold prepared with a combination of direct dissolution and salt leaching technique. The porous scaffolds are formed when the silk concentration was at least six w/v\%, indicating a minimum silk concentration to produce porous scaffold.

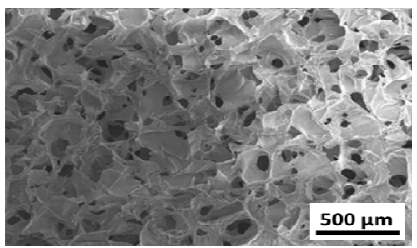

a)

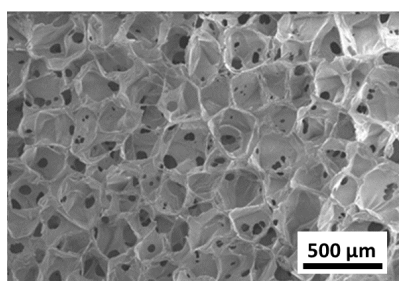

c)

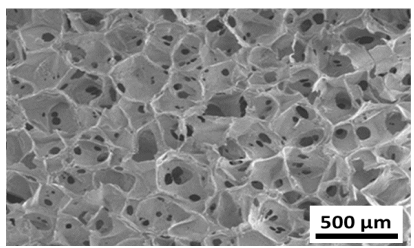

b)

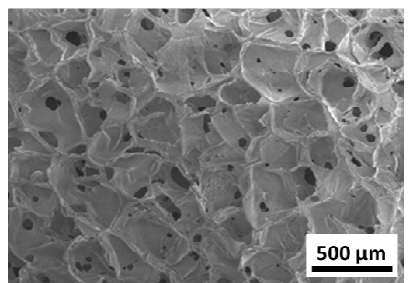

d)
Fig. 2 SEM images of formed scaffold fabricated by salt leaching technique with silk fibroin concentration a) $6 \mathrm{w} / \mathrm{v} \%$, b) $8 \mathrm{w} / \mathrm{v} \%$, c) $10 \mathrm{w} / \mathrm{v} \%$ and d) 12 $\mathrm{w} / \mathrm{v} \%$.

Below this point, NaCl-silk block is disintegrated after immersed in water. An interconnected pore morphology is present in the scaffold with six w/v\%, eight w/v\%, ten w/v\%, and $12 \mathrm{w} / \mathrm{v} \%$. The interconnected pore is important to cellular activity because it is required for nutrition and cellular transportation during cell culture [3]. The resulted pore shapes are rounded instead of the square as seen in the common $\mathrm{NaCl}$ crystal. This is due to partial dissolution of $\mathrm{NaCl}$ surface in formic acid. These phenomena are also found in the salt SF leached scaffold prepared by the traditional dissolution [13].

Table shows salt-leached scaffolds have average pore diameter 261-293 $\mu \mathrm{m}$. This range of pore size is suitable for cartilage regeneration as in agreement with previously reported [15] that showed higher proteoglycan production, SOX9, and COL2A1 gene expression, and type II collagen with a pore size of $200-400 \mu \mathrm{m}$. The pore measurement results also show an increasing average pore size as the silk concentration increased. The pore size formation commonly is regulated by initial salt size and silk concentration [13], [16]. As the $\mathrm{NaCl}$ particle size used in this study is the same, the pore size is regulated by the silk concentration. Higher solvent content on the lower SF concentration will partially dissolve the sodium chloride granule more severe rather than the higher SF content, which has a lower solvent. The more solvent included in the solutions, the more reduction of the salt diameter will occur. As a result, the smaller pore size will be obtained in the lower SF content. Literature shows salt leached SF scaffold using a traditional solvent ( $\mathrm{LiBr}$ or $\left.\mathrm{CaCl}_{2} / \mathrm{Et}-\mathrm{OH} / \mathrm{H}_{2} \mathrm{O}\right)$ resulting in decreasing pore size with increasing SF content which is in contrary with this study [6], [16]. The gelation of SF solution by $\mathrm{NaCl}$ addition when prepared traditional solvent prevent excessive salt 
dissolution [6]. However, silk gelation is not formed in $\mathrm{CaCl}_{2}$-formic acid solutions as reported by [13], which also resulted in this study. As a consequence, the partial dissolution of $\mathrm{NaCl}$ particle is more pronounced.

TABLE I

MEASURED PORE SIZE $(\mu \mathrm{M})$ OF THE SALT LEACHED SILK FIBROIN SCAFFOLD.

\begin{tabular}{|c|c|c|c|c|c|c|}
\hline \multirow{2}{*}{$\begin{array}{l}\text { Salt } \\
\text { Size } \\
(\mu \mathrm{m})\end{array}$} & \multicolumn{6}{|c|}{ Silk fibroin concentration (w/v \%) } \\
\hline & 2 & 4 & 6 & 8 & 10 & 12 \\
\hline $250 \pm 58$ & NF & NF & $261 \pm 67$ & $275 \pm 46$ & $286 \pm 49$ & $\begin{array}{c}293 \pm \\
61\end{array}$ \\
\hline
\end{tabular}

NF: Scaffolds were not formed.

\section{B. Scaffold Characterization}

1) Fourier Transformation Infrared (FTIR) Spectroscopy and X-ray diffraction (XRD): FTIR and XRD results are shown in Three a) and Fig. 3 b), respectively. The

2)

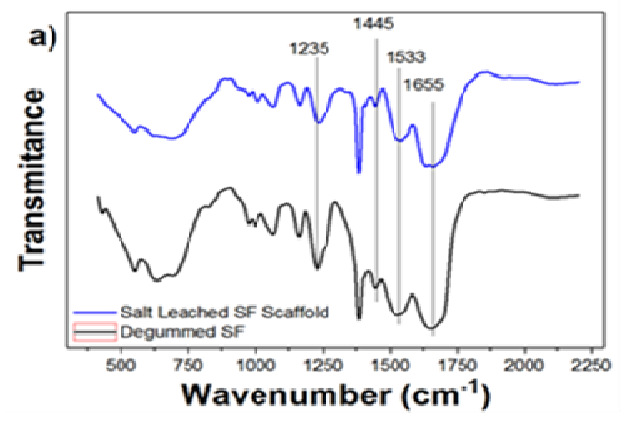

Fig. 3 Structural analysis of the salt leached scaffolds and degummed silk by a) FTIR and b) XRD

3) Contact Angle and Water Uptakes: Static contact angle measurement on the SF film prepared with various SF concentration is presented in Table. The contact angle of SF films is between $49-58^{\circ}$. This result shows the hydrophilic characteristics of silk fibroin and comparable the contact angle of silk fibroin prepared from traditional dissolution methods [19], [20]. Higher the SF concentration increased contact angle indicates lower wettability and lower biocompatibility of the SF film due to development of higher crystalline structure [19]. The hydrophilic behavior of silk fibroin prepared using direct dissolution should be suitable for tissue engineering application.

\section{TABLE II}

MEASURED CONTACT ANGLE OF SF FILM WITH VARIOUS SF CONCENTRATION

\begin{tabular}{|l|c|c|c|c|c|}
\hline & \multicolumn{4}{|c|}{ Measured data } & Literature \\
\hline $\begin{array}{l}\text { Silk } \\
\text { Concentration }\end{array}$ & $\begin{array}{c}6 \\
\mathrm{w} / \mathrm{v} \%\end{array}$ & $\begin{array}{c}8 \\
\mathrm{w} / \mathrm{v} \%\end{array}$ & $\begin{array}{c}10 \\
\mathrm{w} / \mathrm{v} \%\end{array}$ & $\begin{array}{c}12 \\
\mathrm{w} / \mathrm{v} \%\end{array}$ & $\begin{array}{c}5 \mathrm{w} / \mathrm{v} \% \\
{[20]}\end{array}$ \\
\hline $\begin{array}{l}\text { Contact Angle } \\
\left({ }^{\circ}\right)\end{array}$ & 49 & 53 & 55 & 58 & 55 \\
\hline
\end{tabular}

Fig. 4 shows water uptake of salt leached SF scaffolds after 24 hours immersion in water. Water uptake decreased with increasing SF concentration. SF concentration influence the water uptake, regulated by wettability properties. Higher silk SF content indicates more hydrophobic behavior as in line with static contact angle measurement, which reduced

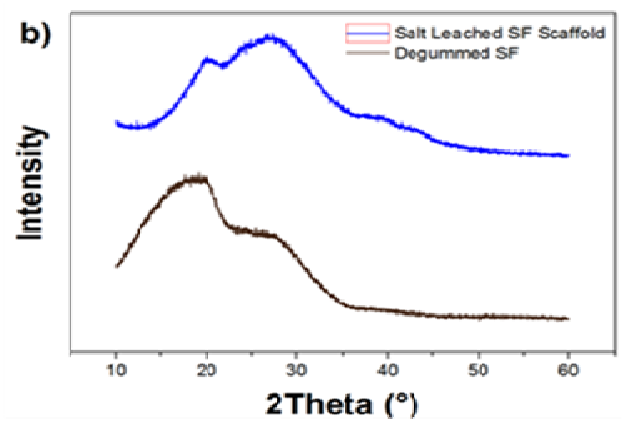

FTIR spectra show amide I and II regions in both SF degummed fiber and SF salt leached scaffold. Peaks observed at $1655 \mathrm{~cm}^{-1}$ (amide I) and $1535 \mathrm{~cm}^{-1}$ (amide II) are corresponding to the amorphous $\alpha$-helix structure. The adsorption peaks at $1445 \mathrm{~cm}^{-1}$ and $1235 \mathrm{~cm}^{-1}$ are belonged to crystalline $\beta$-sheet structure [17], [18]. XRD analysis shows peak at $20.7^{\circ}$ and $27.7^{\circ}$ in both degummed silk fiber and salt-leached scaffolds (Fig. $3 \mathrm{~b}$ ). The first peak indicates the $\beta$-sheet crystalline region and the second peak indicated the amorphous region. The silk fiber has higher crystalline region as the native characteristics of silk fibroin. However, the crystallinity of salt leached SF scaffold decreases to $41.5 \%$ compared to degummed SF fiber $55.6 \%$. The XRD results of the salt leached scaffold are similar to result from a previous report [13]. FTIR and XRD results reveal the silk fibroin secondary structure on the silk fiber and the scaffolds is remain similar although there is a decrease in crystallinity in salt leached SF scaffolds.

the water binding. The water uptake of the scaffolds is 81$96 \%$, which is relatively high for tissue engineering applications as reported by Zhang [16] that obtained 75-95\% water uptake. Water uptake of the aqueous-derived scaffolds in another study [13] is about 93\% regardless of the concentration of silk fibroin and pore size. This is due to high water-binding ability, which attributed to the porous structure inside the scaffold.

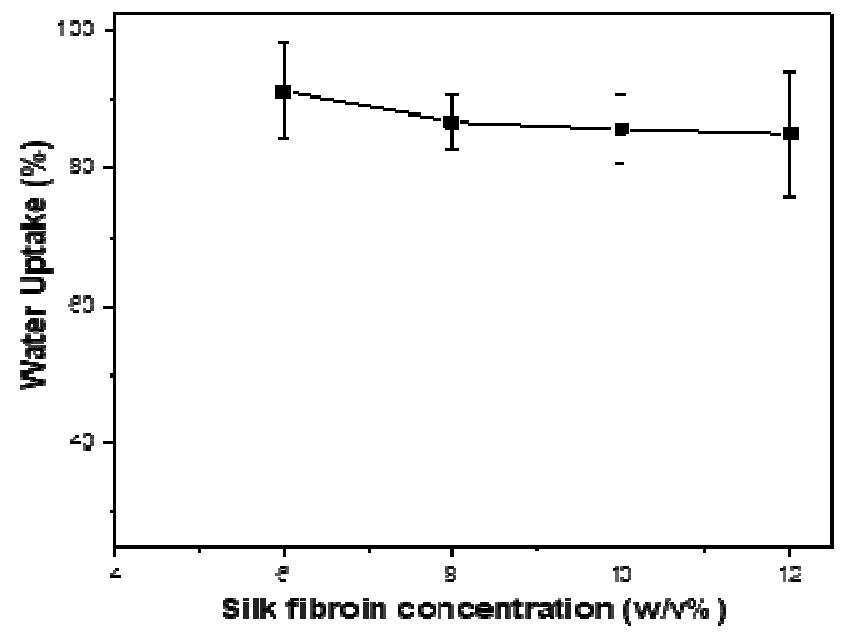

Fig. 4 Water uptake properties of salt leached fibroin scaffold with different silk concentration. 


\section{Biodegradability Assessment}

Fig. 5 shows the remaining mass of the scaffolds prepared with $6,8,10$, and $12 \mathrm{w} / \mathrm{v} \%$ silk after 14 days incubation in Protease XIV (1U/mL). As the SF concentration increased, the mass loss of the scaffolds was decreased. The scaffolds with six w/v\% show the highest degradation up to $64 \%$ after 14 days incubation. The scaffolds with $12 \mathrm{w} / \mathrm{v} \%$ show the lowest degradation up to $34 \%$ respectively after 14 days of incubation. The result shows a trend that more silk fibroin content on the scaffold will have lower degradation rate, and similar with a previous report [13]. This is due to the higher number of attacking site stand in the higher silk content. The biodegradability assessment confirmed biodegradable properties of SF scaffold which essential in biomedical application, especially in tissue engineering application.

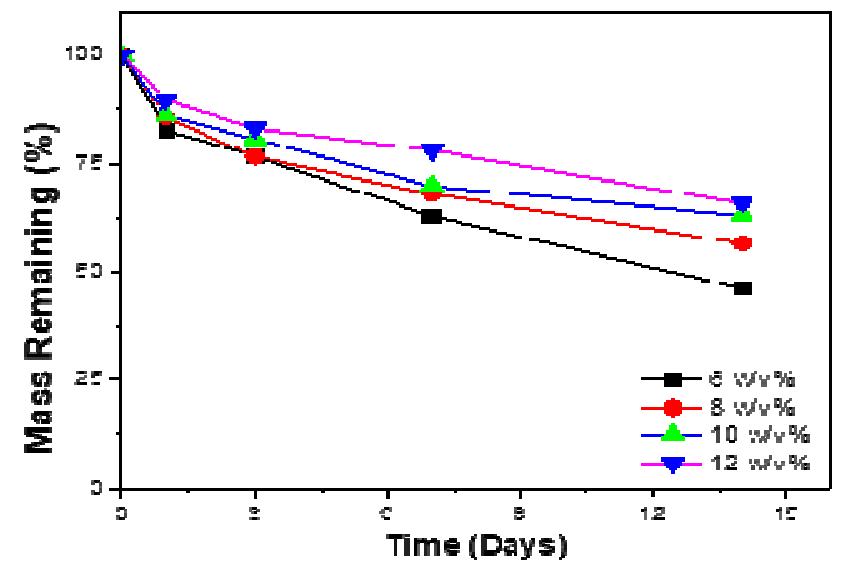

Fig. 5 Degradation behavior of salt leached SF scaffolds 6, 8, 10 and 12 w/v\% SF contents with $200 \mu \mathrm{m}$ pore size scaffolds incubated in Protease XIV.

\section{Biocompatibility Assessment}

Fig. 6 presents cell attachment after 1 day of culture on the scaffolds with $6 \mathrm{w} / \mathrm{v} \%$ and $12 \mathrm{w} / \mathrm{v} \%$, indicates that the scaffolds support the Adipose-derived Stem Cells (AdSCs) cell attachments. This result is also in agreement with previous studies [7], which showed marrow stromal cells (MSCs) adhesion SF film prepared by $\mathrm{CaCl}_{2} /$ formic acid solution as a solvent. The cell spreading was also observed on SF scaffold by extension of the cell lamellipodia or cytoskeleton to the scaffold surfaces. Such kind of attachment activity shows the cells is strongly attached to the silk scaffold as also shown in the previous study by Minoura [21]. This activity demonstrated a good response from the cell to materials, suggesting that salt leaching methods used to produce this scaffold did not generate non-toxic properties. The ability of adherent type cell to attach to the surface of the material was for the cell to subsequent biological activity such as migration, proliferation, and differentiation [22]. AdSCs is currently attracted great interest in the cartilage regeneration since it can differentiate into chondrogenic lineage [23]. The chondrogenic differentiation of ADSCs was observed on the salt leached silk fibroin scaffold, which prepared using traditional dissolution [24]. The scaffolds showed an ability to provide a suitable environment for human adipose-derived stem cells' survival and chondrogenesis. Another finding also supported by the studies that showed cartilage tissue formation when the AdSCs mixed with fibrin glue [25], as well as seeded in PRP-derived scaffold [23] or fibroblastderived extracellular matrix [26]. This result confirms the scaffold resulted in this study has good biocompatibility to the AdSCs and were suitable to be used in cartilage tissue engineering.
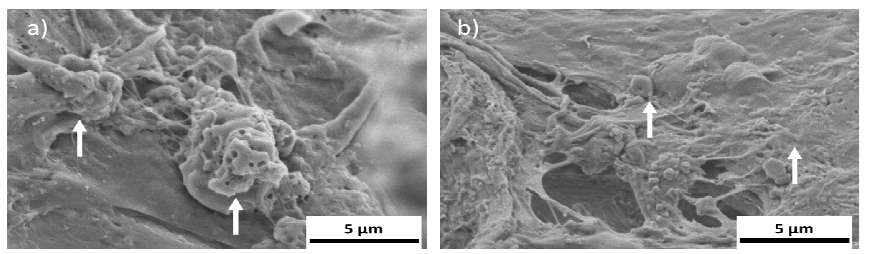

Fig. 6 SEM images of cell attachment on the salt leached scaffolds prepared with a) $6 \mathrm{w} / \mathrm{v} \%$ and b) $12 \mathrm{w} / \mathrm{v} \%$.

\section{CONCLUSION}

Silk fibroin scaffold fabrication using a combination of direct dissolution in $\mathrm{CaCl}_{2}$ /formic acid and salt leaching techniques has been successfully developed. Highly interconnected porous scaffolds resulted with pore size diameter of 261-293 $\mu \mathrm{m}$ and suitable for tissue engineering application. FTIR and XRD analysis of the scaffolds showed characteristics of silk fibroin $\alpha$-helix amorphous and $\beta$-sheet crystalline structure and comparable to the silk fiber. Water contact angle and water uptakes evaluation showed good hydrophilic properties of the scaffolds. The scaffolds degraded under proteolytic enzymes in Protease XIV, indicating biodegradable properties which are essential in tissue engineering application. Observation of cell attachment confirms the scaffold has good biocompatibility to Adipose-derived Stem Cells (AdSCs) and are suitable to be used in cartilage tissue engineering.

\section{ACKNOWLEDGMENTS}

This research was financially funded from The Asahi Glass Foundation, Japan, in the Overseas Research Grant program organized by LPPM ITB.

\section{REFERENCES}

[1] Y. Liu, G. Zhou, and Y. Cao, "Recent Progress in Cartilage Tissue Engineering-Our Experience and Future Directions," Engineering, vol. 3, no. 1. pp. 28-35, 2017.

[2] J. Lanza, R., Langer, R., Vacanti, Principle of Tissue Engineering, vol. Third Edit. 2007.

[3] F. J. O'Brien, "Biomaterials \& scaffolds for tissue engineering," Mater. Today, vol. 14, no. 3, pp. 88-95, 2011.

[4] B. Kundu, R. Rajkhowa, S. C. Kundu, and X. Wang, "Silk fibroin biomaterials for tissue regenerations," Adv. Drug Deliv. Rev., vol. 65, no. 4, pp. 457-470, 2013.

[5] E. A. Makris, A. H. Gomoll, K. N. Malizos, J. C. Hu, and K. A. Athanasiou, "Repair and tissue engineering techniques for articular cartilage," Nat. Rev. Rheumatol., vol. 11, no. 1, pp. 21-34, 2014.

[6] R. Nazarov, H.-J. Jin, and D. L. Kaplan, "Porous 3-D Scaffolds from Regenerated Silk Fibroin," Biomacromolecules, vol. 5, no. 3, pp. 718-726, May 2004.

[7] F. Zhang, X. You, H. Dou, Z. Liu, B. Zuo, and X. Zhang, "Facile fabrication of robust silk nanofibril films via direct dissolution of silk in CaCl2-formic acid solution," ACS Appl. Mater. Interfaces, vol. 7, no. 5 , pp. 3352-3361, 2015.

[8] F. Zhang et al., "Regeneration of high-quality silk fibroin fiber by wet spinning from CaCl2-formic acid solvent," Acta Biomater., vol. 12, no. 1, pp. 139-145, 2015.

[9] H. J. Park et al., "Fabrication of 3D porous silk scaffolds by particulate (salt/sucrose) leaching for bone tissue reconstruction," Int. 
J. Biol. Macromol., vol. 78, no. Supplement C, pp. 215-223, 2015.

[10] S. Mohanty et al., "Fabrication of scalable tissue engineering scaffolds with dual-pore microarchitecture by combining 3D printing and particle leaching," Mater. Sci. Eng. C, vol. 61, no. Supplement C, pp. 180-189, 2016.

[11] K. Kanimozhi, S. K. Basha, and V. S. Kumari, "Fabrication of chitosan based hybrid porous scaffolds by salt leaching for soft tissue engineering," Surfaces and Interfaces, vol. 1-3, no. Supplement C, pp. 7-12, 2016.

[12] F. Zhou et al., "Silk fibroin-chondroitin sulfate scaffold with immuno-inhibition property for articular cartilage repair," Acta Biomater., vol. 63, no. Supplement C, pp. 64-75, 2017.

[13] U. J. Kim, J. Park, H. Joo Kim, M. Wada, and D. L. Kaplan, "Threedimensional aqueous-derived biomaterial scaffolds from silk fibroin,' Biomaterials, vol. 26, no. 15, pp. 2775-2785, 2005.

[14] M. Li, M. Ogiso, and N. Minoura, "Enzymatic degradation behavior of porous silk fibroin sheets," Biomaterials, vol. 24, no. 2, pp. 357365, 2003.

[15] G.-I. Im, J.-Y. Ko, and J. H. Lee, "Chondrogenesis of Adipose Stem Cells in a Porous Polymer Scaffold: Influence of the Pore Size," Cell Transplant, vol. 21, no. 11, pp. 2397-2405, 2012.

[16] X. Zhang, C. Cao, X. Ma, and Y. Li, "Optimization of macroporous 3-D silk fibroin scaffolds by salt-leaching procedure in organic solvent-free conditions," J. Mater. Sci. Mater. Med., vol. 23, no. 2, pp. 315-324, 2012.

[17] X. Hu, D. Kaplan, and P. Cebe, "Determining beta-sheet crystallinity in fibrous proteins by thermal analysis and infrared spectroscopy," Macromolecules, vol. 39, no. 18, pp. 6161-6170, 2006.

[18] S. Ling, Z. Qi, D. P. Knight, Z. Shao, and X. Chen, "FTIR imaging, a useful method for studying the compatibility of silk fibroin-based polymer blends," Polym. Chem., vol. 4, no. 21, p. 5401, 2013.

[19] X. J. Lian, S. Wang, and H. S. Zhu, "Surface properties and cytocompatibillity of silk fibroin films cast from aqueous solutions in different concentrations," Front. Mater. Sci. China, vol. 4, no. 1, pp. 57-63, 2010.

[20] S. Hofmann et al., "Silk fibroin as an organic polymer for controlled drug delivery," J. Control. Release, vol. 111, no. 1-2, pp. 219-227, 2006.

[21] N. Minoura, S. Aiba, M. Higuchi, Y. Gotoh, M. Tsukada, and Y. Imai, "Attachment and growth of fibroblast cells on silk fibroin." Biochemical and biophysical research communications, vol. 208, no. 2. pp. 511-516, 1995.

[22] J. L. McGrath, "Cell Spreading: The Power to Simplify," Current Biology, vol. 17, no. 10. 2007.

[23] X. Xie et al., "Comparative evaluation of MSCs from bone marrow and adipose tissue seeded in PRP-derived scaffold for cartilage regeneration," Biomaterials, vol. 33, no. 29, pp. 7008-7018, 2012.

[24] H. J. Kim, S.-H. Park, J. Durham, J. M. Gimble, D. L. Kaplan, and J. L. Dragoo, "In vitro chondrogenic differentiation of human adiposederived stem cells with silk scaffolds.," J. Tissue Eng., vol. 3, no. 1, p. $2041731412466405,2012$.

[25] S.-N. Jung et al., "In vivo cartilage formation using chondrogenicdifferentiated human adipose-derived mesenchymal stem cells mixed with fibrin glue." J. Craniofac. Surg., vol. 21, no. 2, pp. 468-72, 2010 .

[26] K. Dzobo et al., "Fibroblast-derived extracellular matrix induces chondrogenic differentiation in human adipose-derived mesenchymal stromal/stem cells in vitro," Int. J. Mol. Sci., vol. 17, no. 8, 2016. 